\title{
A new biogenerated Rh-based catalyst for aqueous biphasic hydroformylation
}

\author{
Stefano Paganelli ${ }^{\mathrm{a}, *}$, Oreste Piccolo ${ }^{\mathrm{b}}$, Franco Baldi ${ }^{\mathrm{a}}$, Michele Gallo ${ }^{\mathrm{a}}$, Riccardo Tassini ${ }^{\mathrm{a}}$, \\ Marzio Rancan ${ }^{\mathrm{c}, \mathrm{d}}$, Lidia Armelao ${ }^{\mathrm{d}}$ \\ a Dipartimento di Scienze Molecolari e Nanosistemi, Università Ca' Foscari Venezia, Via Torino 155, 30170 Venezia Mestre, Italy \\ b SCSOP, Via Bornò 5, 23896 Sirtori, LC, Italy \\ c Dipartimento di Scienze Chimiche and IENI-CNR, Università di Padova, Via Marzolo 1, 35131 Padova, Italy \\ d IENI-CNR and INSTM, Dipartimento di Scienze Chimiche, Università di Padova, Via Marzolo 1, 35131 Padova, Italy
}

\section{A R T I C L E I N F O}

\section{Article history:}

Received 8 July 2015

Received in revised form 31 July 2015

Accepted 1 August 2015

Available online 8 August 2015

\section{Keywords:}

Rhodium

Biphasic hydroformylation

Catalyst

Klebsiella oxytoca

Polysaccharide

\begin{abstract}
A B S T R A C T
A new bio-generated rhodium based system embedded in a peculiar polysaccharide matrix (Rh-EPS), was obtained and purified from cultures of bacterial cells of Klebsiella oxytoca DSM 29614. The product was analyzed with different techniques to obtain information on its structure-property correlation. In order to determine its catalytic activity and selectivity in the aqueous biphasic hydroformylation some olefins were chosen as model substrates, obtaining fine-good results.
\end{abstract}

() 2015 Elsevier B.V. All rights reserved.

\section{Introduction}

Hydroformylation is one of the most important industrial reactions catalyzed by soluble metal complexes [1]. The most efficient catalysts in terms of both activity and selectivity are rhodium complexes, capable to operate under mild conditions [1]. The major drawback of this homogeneous process is the separation of the expensive catalyst from the product mixture that requires an energy intensive process such as distillation. For this reason and for environmental aspects of the chemical production, liquid-liquid two-phase systems have been developed over the last years, with the catalyst confined in one phase and the product in the other one $[2,3]$. In particular, the use of environmentally more benign solvents as water has been developed [2,3] and the hydroformylation process represents one of the most striking examples of this catalytic methodology [1-4]. The use of natural compounds, such as aminoacids, peptides, proteins and sugars as ligands to maintain metallic species soluble and active in aqueous biphasic systems was deeply investigated [5-15]. Since bacterial cells may often synthesize and secret polysaccharides [16], recently we envisaged a new way of using bacteria to produce carbohydrates able to bind metals during their growing in the presence of suitable metal salts. In particular Klebsiella oxytoca DSM 29614 (ex strain BAS-10) strain, isolated from the acid

\footnotetext{
* Corresponding author.

E-mail address: spag@unive.it (S. Paganelli).
}

mine drainage of pyrite mines and able to produce a peculiar exopolysaccharide (EPS), constituted by a branched heptameric repeating structure [17], was investigated with success by some of us to generate some metal-polysaccharide catalysts $[18,19]$. In this study, a new bio-generated Rh based catalyst (Rh-EPS) was produced in order to determine its activity and selectivity in the aqueous biphasic hydroformylation of some olefins chosen as model substrates.

\section{Experimental section}

\subsection{Materials and instrumentation}

$\mathrm{NaHCO}_{3}, \mathrm{NH}_{4} \mathrm{Cl}, \mathrm{MgSO}_{4} \cdot 7 \mathrm{H}_{2} \mathrm{O}, \mathrm{NaH}_{2} \mathrm{PO}_{4}, \mathrm{KCl}, \mathrm{Na}$-citrate, styrene, 1octene, and toluene were Aldrich products. 2-allyl-5-ethylthiophene (IX) and 1-[(5-ethyl)thiophen-2-yl]propene (XII) were prepared with $60 \%$ and $92 \%$ yields, respectively, using a Pd-catalyzed cross-coupling reaction of the Grignard reagent obtained from 2-bromo-5-ethylthiophene with 1-bromo-2-propene or with 1-bromo-1-propene, respectively, according to a procedure described for similar compounds $[20,21] . \mathrm{RhCl}_{3}$ was obtained from Chimet S.p.A. (Italy). GC analyses were carried out on an Agilent 6850A gaschromatograph (HP1 column $30 \mathrm{~m} \times 0.32 \mathrm{~mm} \times 0.25 \mu \mathrm{m})$. Atomic absorption measurements were carried out by using a Perkin Elmer AANALYST 100 instrument. TEM analyses were performed on a JEOL JEM 100b microscope. IR spectra ( $\mathrm{KBr}$ pellets) were recorded on an FTIR Nicolet Magna 750 instrument. 


\subsection{Biogenerated catalyst preparation}

\subsubsection{Anaerobic cultivation}

The K. oxytoca DSM 29614 was retrieved from cryovials kept at $-80{ }^{\circ} \mathrm{C}$ in $25 \%$ glycerol in Nutrient broth (Difco). The production of Rh-EPS was made in NAC medium containing per liter: $2.5 \mathrm{~g} \mathrm{NaHCO}_{3}$, $1.5 \mathrm{~g} \mathrm{NH}_{4} \mathrm{Cl}, 1.5 \mathrm{~g} \mathrm{MgSO}_{4} \cdot 7 \mathrm{H}_{2} \mathrm{O}, 0.6 \mathrm{~g} \mathrm{NaH}_{2} \mathrm{PO}_{4}, 0.1 \mathrm{~g} \mathrm{KCl}$ and $50 \mathrm{mM}$ $\left(14.7 \mathrm{~g} \cdot \mathrm{l}^{-1}\right)$ Na-citrate, and finally it was buffered at $\mathrm{pH} 7.6$ with $\mathrm{NaOH}$. The NAC medium prepared in 11 Pyrex bottle was cooled down under nitrogen flux and then it was sealed. A fresh culture was inoculated (1:100 v:v) in and incubated at $30^{\circ} \mathrm{C}$. At the beginning of stationary growth phase (2 days) the culture was amended with $50 \mathrm{mg}$ of total rhodium as $\mathrm{RhCl}_{3}$. The medium was kept under anaerobic conditions by $\mathrm{N}_{2}$ fluxing. At the end rhodium, bound to the exopolysaccharide, precipitated from the culture to the bottom bottle as Rh-EPS.

\section{3. $\boldsymbol{R h}$-EPS purification}

Bacterial cell residues were eliminated by centrifugation at $4000 \mathrm{~g}$ per $25^{\prime}$ and then the supernatant was treated with $800 \mathrm{ml}$ of cooled ethyl alcohol (95\%) to precipitate all Rh-EPS. Salt residues were removed by washing Rh-EPS three times with distilled water. The colloidal material was dried out under vacuum to obtain Rh-EPS, as a solid dry material, and was stored at $4{ }^{\circ} \mathrm{C}$.

\subsection{Biogenerated catalyst characterization}

\subsubsection{Content of Rh in $\boldsymbol{R h}$-EPS}

A Rh-EPS sample was analyzed by atomic absorption after treatment with aqua regia to determine the total Rh concentration: the obtained value was $0.8 \%$.

\subsubsection{Transmission electron microscope observations}

To observe the electron dense rhodium in EPS, several specimens were prepared for transmission electron microscopy (TEM). An amount of $10 \mathrm{mg}$ of dried catalyst was suspended in $5 \mathrm{ml}$ distilled water and, after $10 \mathrm{~min}$ in ultrasonic bath, $10 \mu \mathrm{l}$ of the suspension was mounted on a platinum grid which was previously coated with a Formvar biofilm. The liquid was evaporated at room temperature and the layered specimen on the grid was observed by transmission electron microscopy operating under standard conditions.

\subsubsection{X-ray photoelectron spectroscopy}

XPS was used as the main tool to assess the surface chemical composition of the samples before and after the catalytic process. Analyses were performed on a Perkin-Elmer $\Phi$ 5600-ci spectrometer using non-monochromatized $\mathrm{Al} \mathrm{K}_{\alpha}$ radiation $(1486.6 \mathrm{eV})$. The spectrometer was calibrated by assuming the binding energy (BE) of the $A u 4 f_{7 / 2}$ line at $83.9 \mathrm{eV}$ with respect to the Fermi level. Survey scans were obtained in the $0-1300 \mathrm{eV}$ range. Detailed scans were recorded for the Rh3d, N1s, O1s, P2p, Mg2s, Na1s and C1s regions. The BEs values were corrected for charging effects by assigning to the $\mathrm{C} 1 \mathrm{~s}$ peak associated with adventitious hydrocarbons a value of $284.8 \mathrm{eV}$ [22]. Samples were mounted as finely grounded powders on steel holders and introduced directly in the fast-entry lock system of the XPS analytical chamber. No sizeable sign of sample degradation was observed under X-ray irradiation.

\subsubsection{Powder X-ray diffraction}

PXRD was used to investigate the crystalline phases before and after the catalytic process. PXRD measurements were carried out by means of a Bruker D8 Advance diffractometer equipped with a Göbel mirror and a $\mathrm{Cu}-\mathrm{K} \alpha$ source $(40 \mathrm{kV}, 40 \mathrm{~mA})$. PXRD patterns of struvite and bobierrite were simulated by means of Mercury 3.5.1 software with a full width at half maximum (FWHM) of $0.3^{\circ}$ and $0.5^{\circ}$ (in $2 \theta$ ), respectively.
Table 1

Aqueous biphasic hydroformylation of styrene (I) catalyzed by Rh-EPS.

\begin{tabular}{lclc}
\hline Entry & Conv. $(\%)$ & II yield $(\%)$ & III yield $(\%)$ \\
\hline 1 & 100.0 & 93.0 & 7.0 \\
$2^{\mathrm{b}}$ & 99.0 & 93.0 & 6.0 \\
$3^{\mathrm{b}}$ & 78.0 & 73.0 & 5.0 \\
$4^{\mathrm{b}}$ & 49.0 & 46.0 & 3.0 \\
$5^{\mathrm{c}}$ & 100.0 & 87.0 & 13.0 \\
\hline
\end{tabular}

Reaction conditions: substrate $=0.26 \mathrm{mmol}$; substrate $/ \mathrm{Rh}$ (molar ratio) $=1000 / 1$; $\mathrm{p}(\mathrm{CO})=\mathrm{p}\left(\mathrm{H}_{2}\right)=3 \mathrm{MPa} ; \mathrm{T}=60{ }^{\circ} \mathrm{C} ; \mathrm{t}=18 \mathrm{~h} ; \mathrm{H}_{2} \mathrm{O}=2 \mathrm{ml}$; toluene $=2 \mathrm{ml}$. ${ }^{\mathrm{b}}$ Experiment carried out by using the catalytic phase recovered from the previous run. ${ }^{\mathrm{c}}$ Experiment carried out at the above reaction conditions but in the presence of $\mathrm{RhCl}_{3}$ as catalyst.

\subsection{Aqueous biphasic hydroformylation experiments}

All the reactions were carried out following a procedure similar to that below described for the Rh-EPS catalyzed hydroformylation of styrene (I). Experimental details are reported in Tables 1-3.

\subsubsection{Aqueous biphasic hydroformylation of styrene (I)}

In a Schlenk tube, $3.4 \mathrm{mg}(0.26 \mu \mathrm{mol}$ of Rh) of Rh-EPS were stirred under nitrogen in $2 \mathrm{ml}$ of distilled water for about $10^{\prime}$. A solution of $27.0 \mathrm{mg}(0.26 \mathrm{mmol})$ of freshly distilled styrene (I) in $2 \mathrm{ml}$ of toluene was then added to the aqueous phase. The Schlenk tube was then transferred into a $150 \mathrm{ml}$ stainless steel autoclave under nitrogen, pressurized with $6 \mathrm{MPa}$ of syngas $\left(\mathrm{CO} / \mathrm{H}_{2}=1\right)$ and stirred for $18 \mathrm{~h}$ at $60{ }^{\circ} \mathrm{C}$ (Table 1). The reactor was then cooled to room temperature and the residual gases released. Diethyl ether was added and the organic phase was separated, dried on $\mathrm{Na}_{2} \mathrm{SO}_{4}$ and analyzed by GC and GC-MS. The catalytic aqueous phase was recycled for further experiments after addition of fresh styrene (I).

\section{Results and discussion}

The strain K. oxytoca DSM 29614 produces an exopolysaccharide (EPS) with the following structure: 4 rhamnose (Rha), 2 glucuronic acids (GlcA) and 1 galactose (Gal) bound by glycosidic bonds as following [17]:

$$
\begin{gathered}
2)-\alpha-\text { Rha- }(1 \rightarrow 3)-\beta-\text { Gal- }(1 \rightarrow 2)-\alpha-\text { Rha- }(1 \rightarrow 4)-\beta-\text { GlcA- }(1 \rightarrow 3)-\alpha-\text { Rha- }(1 \rightarrow 3)-\alpha-\text { Rha- }(1 \rightarrow \\
4 \\
\text { EPS } \\
\beta-G l c A
\end{gathered}
$$

which has neither glucose nor fucose, which are in general present in common colanic acid [23]. The latter in Enterobacteriaceae is a polyanionic heteropolysaccharide containing a repeat unit with D-glucose, L-fucose, D-galactose, and D-glucuronate sugars. This anomalous colanic acid analogue secreted by $K$. oxytoca is likely the result of adaptation to high concentrations of heavy metals, typical of acid drainage of pyrite mines. EPS binds iron and other metals during the bacterial growth, as defense mechanism to metal poisoning [23]. The metal is sequestered by the exopolymeric structure, which prevents the metal to

Table 2

Aqueous biphasic hydroformylation of 1-octene (IV) and 2-octene (V) catalyzed by Rh-EPS.

\begin{tabular}{lllllll}
\hline Entry & Substrate & $\begin{array}{l}\text { Conv. } \\
(\%)\end{array}$ & $\begin{array}{l}\text { VI yield } \\
(\%)\end{array}$ & $\begin{array}{l}\text { VII yield } \\
(\%)\end{array}$ & $\begin{array}{l}\text { VIII yield } \\
(\%)\end{array}$ & $\begin{array}{l}\text { V yield } \\
(\%)\end{array}$ \\
\hline 1 & IV & 99.0 & 54.2 & 36.5 & 1.4 & 6.9 \\
$2^{\text {a }}$ & IV & 98.6 & 53.7 & 38.6 & 0.8 & 5.5 \\
$3^{\text {a }}$ & IV & 95.5 & 47.1 & 35.9 & nd & 12.5 \\
$4^{\text {b }}$ & IV & 0 & - & - & - & - \\
5 & V & 20.6 & nd & 14.9 & 5.7 & \\
$6^{\text {a }}$ & V & 18.6 & nd & 13.9 & 4.7 & \\
\hline
\end{tabular}

Reaction conditions: substrate $=0.65 \mathrm{mmol}$; substrate $/ \mathrm{Rh}$ (molar ratio) $=1000 / 1$; $\mathrm{p}(\mathrm{CO})=\mathrm{p}\left(\mathrm{H}_{2}\right)=3 \mathrm{MPa} ; \mathrm{T}=60{ }^{\circ} \mathrm{C} ; \mathrm{t}=22 \mathrm{~h} ; \mathrm{H}_{2} \mathrm{O}=2 \mathrm{ml}$; Toluene $=2 \mathrm{ml}$.

a Experiment carried out by using the catalytic phase recovered from the previous run.

b $\mathrm{H}_{2} \mathrm{O}=0 \mathrm{ml}$; Toluene $=4 \mathrm{ml}$. nd = not detected in the reaction mixture. 
Table 3

Aqueous biphasic hydroformylation of 2-allyl-5-ethylthiophene (IX) catalyzed by Rh-EPS.

\begin{tabular}{lllll}
\hline Entry & Conv. (\%) & X yield (\%) & XI yield $(\%)$ & XII yield (\%) \\
\hline 1 & 96.0 & 47.0 & 45.5 & 3.5 \\
$2^{\text {a }}$ & 23.4 & 12.0 & 11.4 & nd \\
$3^{\text {a }}$ & 8.2 & 4.5 & 3.7 & nd \\
\hline
\end{tabular}

Reaction conditions: substrate $=0.65 \mathrm{mmol}$; substrate $/ \mathrm{Rh}$ ( molar ratio $)=1000 / 1 ; \mathrm{p}(\mathrm{CO})=$ $\mathrm{p}\left(\mathrm{H}_{2}\right)=3.5 \mathrm{MPa} ; \mathrm{T}=60^{\circ} \mathrm{C} ; \mathrm{t}=22 \mathrm{~h} ; \mathrm{H}_{2} \mathrm{O}=2 \mathrm{ml}$; toluene $=2 \mathrm{ml}$.

a Experiment carried out by using the catalytic phase recovered from the previous run. nd $=$ not detected in the reaction mixture.

come into direct contact with cell membranes and even less with the cytoplasm. To support the hypothesis that also in this case rhodium is embedded in the polysugar moiety we compared the IR spectra of $\mathbf{R h}$ EPS and EPS (Fig. 1); they show different patterns, and the most evident difference is the peak at about $1000 \mathrm{~cm}^{-1}$ in Rh-EPS due to the asymmetric stretching of a $\mathrm{P}-\mathrm{O}-\mathrm{C}$ group of an organic phosphate [24].

The addition of rhodium probably causes the formation of organic phosphates because of an intense phosphatase activity (data not shown) which is likely triggered by $\mathrm{Rh}^{3+}$ toxicity. The precipitation of metals by phosphates was found also in Citrobacter sp [25,26]. So the secretion of exopolysaccharide and phosphatase activity explains the high resistance of DSM 29614 to heavy metal cations. XPS analysis on Rh-EPS confirmed the presence of phosphorous along with carbon, nitrogen, alkaline and alkaline-earth cations $\left(\mathrm{Na}^{+}, \mathrm{Mg}^{2+}\right)$. The P2p line is centered at $\mathrm{BE}$ values (ca. $133 \mathrm{eV}$ ) typical for phosphate species [27] and the N1s region at $400.3 \mathrm{eV}$ is associated with ammonium salts. At variance, unfortunately, rhodium is not revealed likely due to its low concentration. To confirm the presence of inorganic phosphates in Rh-EPS and to investigate the crystalline phases before and after the catalytic process PXRD characterization was performed. The Rh-EPS PXRD pattern before (a) and after (b) the hydroformylation experiments is reported in Supplementary material. The major crystalline phase in the as prepared catalyst is ascribed to struvite, i.e. $\mathrm{MgNH}_{4} \mathrm{PO}_{4} \cdot\left(\mathrm{H}_{2} \mathrm{O}\right)_{6}$, JCPDS card no. 71-2089 (a). The struvite simulated PXRD pattern $\left(\mathrm{FWHM}=0.3^{\circ}\right.$ ) well reproduces the major peaks. Some peaks, marked with asterisks, are not ascribed to $\mathrm{MgNH}_{4} \mathrm{PO}_{4} \cdot\left(\mathrm{H}_{2} \mathrm{O}\right)_{6}$ but could be related to the presence of a mixture of minor crystalline phases of sodium phosphate and sodium hydrogen phosphate hydrate or to the presence of organic phosphates. After the catalytic process Rh-EPS PXRD pattern changes considerably. The two most intense peaks centered at $2 \theta=11.1^{\circ}$ and $12.6^{\circ}$ (b) are indexed as the (021) and (040) reflections of the bobierrite, i.e. $\mathrm{Mg}_{3}\left(\mathrm{PO}_{4}\right)_{2} \cdot(\mathrm{H} 2 \mathrm{O})_{8}$, monoclinic structure (JCPDS card no. 16-0330). Also in this case, the bobierrite simulated PXRD pattern $\left(\mathrm{FWHM}=0.5^{\circ}\right)$ reproduces very well the experimental data. Hence, after the hydroformylation the major crystalline phase changes from an ammonium magnesium phosphate hydrate to a magnesium phosphate hydrate. PXRD analysis again do not show any signal ascribable to rhodium nanoparticles. So this type of analysis was not conclusive to define the interaction of rhodium species with EPS.

More diagnostic were TEM micrographs that show the formation of rhodium nanoparticles embedded in an exopolysaccharidic matrix (Rh-EPS NPs) (Fig. 2). In the inset a magnification of a nanoparticle shows an irregular shape probably due to the presence of nanocrystals of phosphates with elongated dendritic morphology [28] associated with rhodium and exopolysaccharide.

\subsection{Catalytic properties of $\boldsymbol{R h}-\mathbf{E P S}$}

A first set of oxo-experiments was performed on styrene (I) as this aromatic olefin is a widespread studied model substrate for functionalized olefins [1] (Scheme 1). The hydroformylation reactions were carried out in the biphasic medium water/toluene, in the presence of the catalytic system Rh-EPS at $6 \mathrm{MPa}$ of syngas $\left(\mathrm{CO} / \mathrm{H}_{2}=1\right)$ and $60{ }^{\circ} \mathrm{C}$ for $18 \mathrm{~h}$ with a substrate to rhodium molar ratio $=1000$. The catalytic aqueous phase was recycled in three consecutive experiments and the data obtained are reported in Table 1 . The catalytic system was very active, showing complete conversion and chemoselectivity: neither ethylbenzene nor alcohols were formed; also the regioselectivity towards the branched aldehyde, 2-phenylpropanal (II), was very high (93-94\%). The

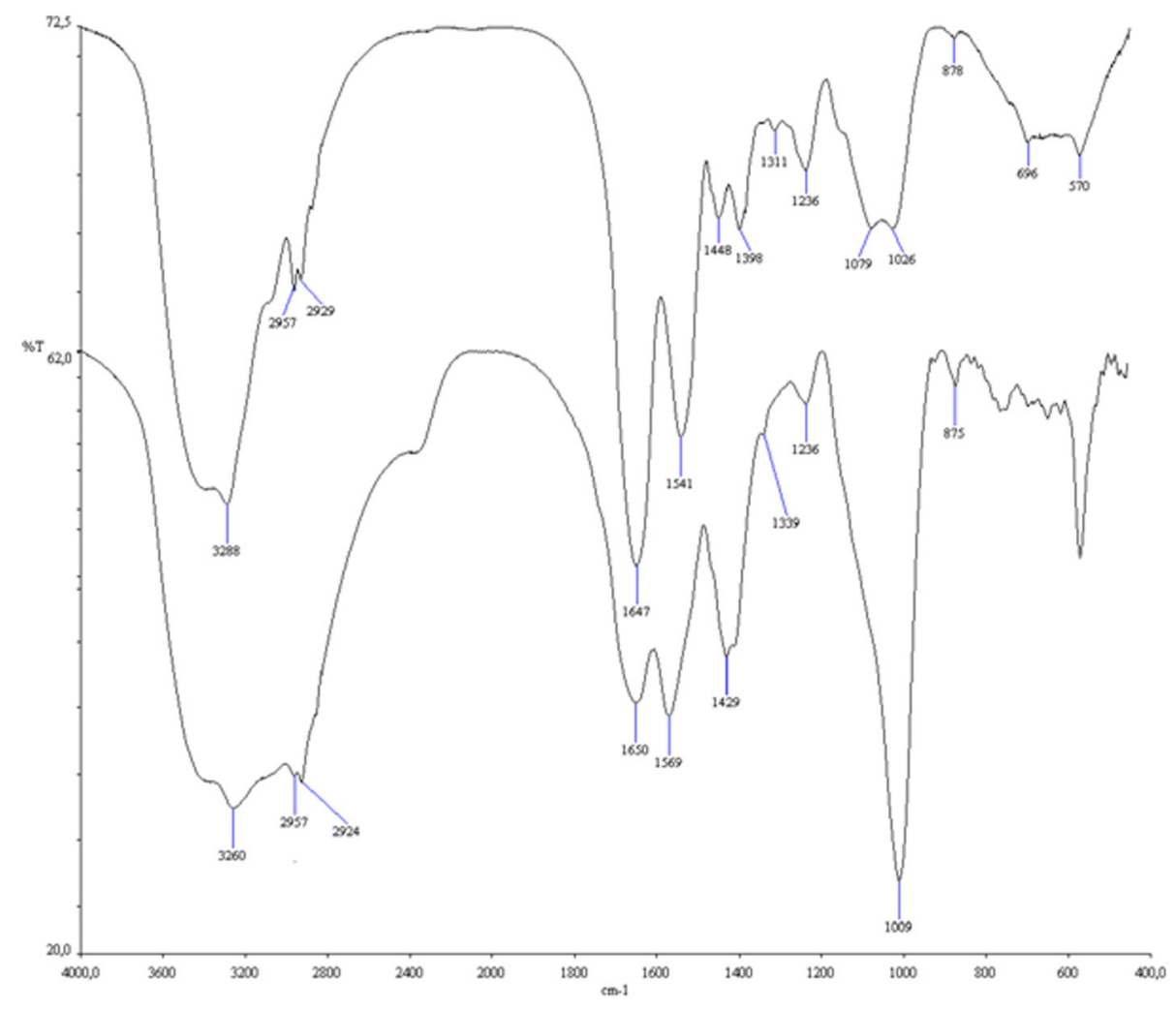

Fig. 1. IR spectrum of EPS (above) and Rh-EPS (below). 


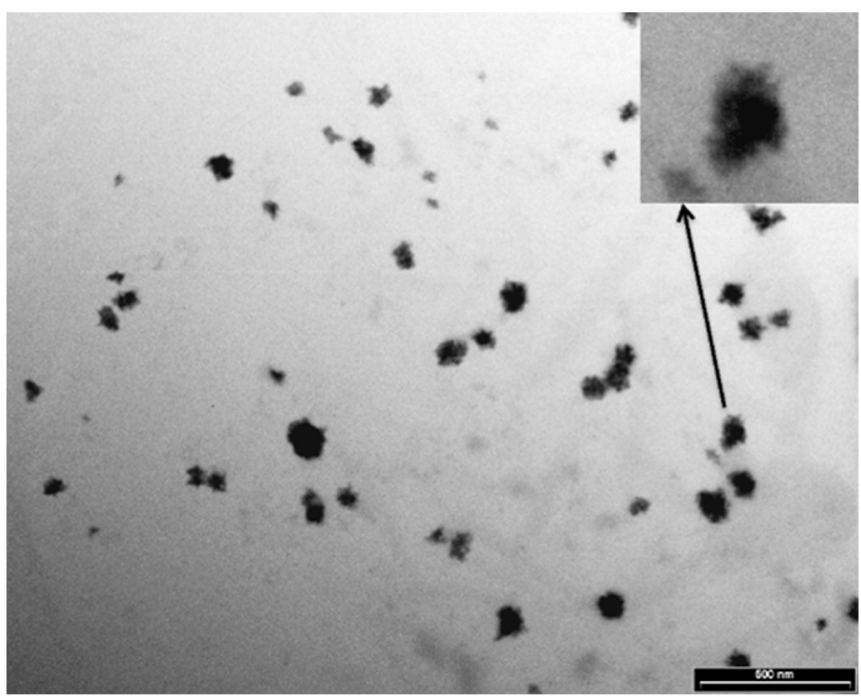

Fig. 2. TEM micrograph of EPS containing Rhodium nanoparticles (electron dense particles), bar $=500 \mathrm{~nm}$. (In set) one elongated particle with $150 \times 90 \mathrm{~nm}$ size.

catalyst activity remained practically unchanged in the first recycle but, unfortunately, a strong decrease was observed starting from the second recycle. Because of the low amount, the decreased activity of the catalyst can be tentatively ascribed both to a mechanical loss and/or to an accidental poisoning due to the presence of oxygen during the phase separation. In all cases, however, chemo- and regioselectivity did not show any significative difference. Noteworthy, when the reaction was carried out at the above reaction conditions but in the presence of $\mathrm{RhCl}_{3}$ as the catalytic precursor, conversion was complete but the regioselectivity was strongly lowered (branched to normal aldehyde $=87 / 13$ ) (Entry 5, Table 1 ); moreover, the catalytic system decomposed and rhodium black was detected in the reaction mixture so making the system not suitable for recycling experiments.

Basing on these results, we carried out the hydroformylation of a linear $\alpha$-olefin, i.e. 1 -octene (IV) (Scheme 2, Table 2). This reaction has been widely studied in the presence of homogeneous or heterogeneous catalysts as well as in aqueous biphasic system $[1,29]$. It is known that both regioselectivity (linear to branched aldehydes ratio) and substrate isomerization strongly depend on the presence of ligands, additives and solvent, among others. For instance, phosphino ligands with large bite angle as Xantphos promote the formation of the linear aldehyde $\mathbf{~ I I}$ and the formation of 2-octene $(\mathbf{V})$ is practically negligible $[1,29]$. When the reaction was carried out in an aqueous biphasic system in

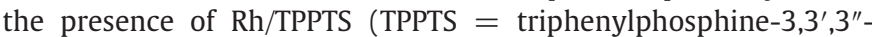
trisulfonic acid trisodium salt) as catalyst but without any additive, only $2 \%$ of aldehydes was produced after $3 \mathrm{~h}$ at $100{ }^{\circ} \mathrm{C}$ and 20 bar of syngas. Despite the very low conversion, about $1.5 \%$ of isomeric olefins was formed [30]. The catalyst activity was strongly increased by adding to the reaction mixture an additive as [OctMim]Br (1-octyl-3methylimidazolium bromide): conversion was practically quantitative and the linear aldehdye VI was preferentially formed. Moreover, the formation of octene isomers was almost suppressed [30]. Recently it has been reported that the hydroformylation of 1-octene catalyzed by rhodium supported on silica: at $120^{\circ} \mathrm{C}$ and low reaction time $\left(30^{\prime}\right)$ the aldehyde yield is good (quantitative conversion, about 70\% aldehyde

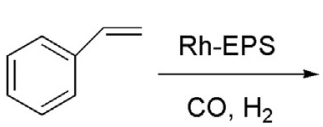

I

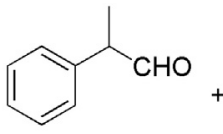

II<smiles>O=CCCc1ccccc1</smiles>

III

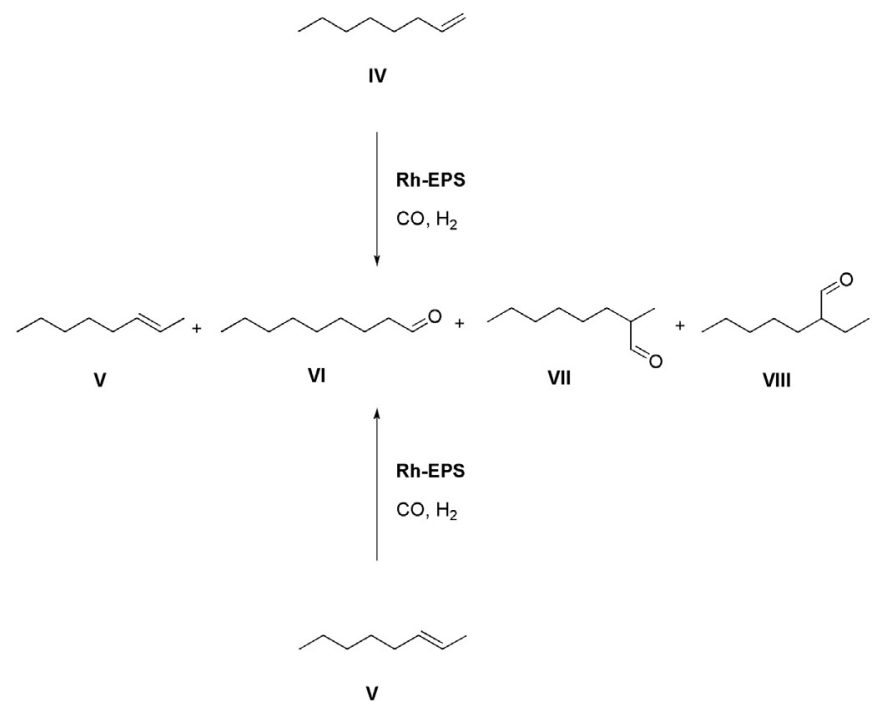

Scheme 2. Hydroformylation of 1-octene (IV) and 2-octene (V).

yield) and the linear to branched aldehyde ratio is about 2.5/1; by increasing the temperature to $140{ }^{\circ} \mathrm{C}, 1$-octene isomerization becomes the prevailing reaction [31]. These literature results indicate that it is difficult to identify a standard protocol to perform this reaction and it is interesting to identify new ligands for Rh species. Hence, we carried out the hydroformylation of 1-octene (IV) in the biphasic water/toluene system in the presence of Rh-EPS at $60^{\circ} \mathrm{C}, 3 \mathrm{MPa}$ of $\mathrm{CO}$ and $3 \mathrm{MPa}$ of $\mathrm{H}_{2}$ for $22 \mathrm{~h}$ : conversion was very high (98\%) and, as expected, $n$-nonanal (VI) was the main product. Besides the two major aldehydes VI and VII, also a very small amount of the isomeric aldehyde VIII was formed, due to the isomerisation of the carbon-carbon double bond: as a matter of fact about $7 \%$ of 2 -octene $(\mathbf{V})$ was detected in the reaction mixture (Entry 1, Table 2). The catalytic phase was reused in two consecutive recycling experiments and its activity was maintained practically unchanged. Noteworthy, analogously to what was observed in the hydrogenation process catalyzed by Pd-EPS [19], also Rh-EPS, though not soluble in water but only suspended in it, is active exclusively in the presence of water. As a matter of fact, when toluene was used as the only reaction medium, no reaction occurred (Entry 4, Table 2). We hypothesize that water swelling of the polymer structure makes rhodium more available for the catalysis process.

Despite its complex structure this catalytic system was shown to be able to hydroformylate also internal double bonds, even if at a low reaction rate; indeed, 2-octene ( $\mathbf{V})$ was subjected to the oxo-process at the above reaction conditions and aldehydes VII and VIII were the sole reaction products (Entry 5, Table 2). The aqueous catalytic phase, when used in a recycling experiment, maintained its activity almost unchanged (Entry 6, Table 2).

Due to our interest in the synthesis of fine chemicals, in particular of fragrances $[8,9,19]$, we finally tested the activity of Rh-EPS in the hydroformylation of 2-allyl-5-ethylthiophene (IX) (Scheme 3, Table 3), being known that some thiophene aldehydes, as compound $\mathbf{X}$ for instance, structurally similar to the fragrance Lioral ${ }^{\circledR}[32]$, have a relevant commercial interest.

The reaction was carried out in the biphasic water/toluene system at $60{ }^{\circ} \mathrm{C}$ and $7 \mathrm{MPa}$ of syngas $\left(\mathrm{CO} / \mathrm{H}_{2}=1\right)$ for $24 \mathrm{~h}$. In these conditions, conversion was very high (96\%) and, surprisingly, the two aldehydes $\mathbf{X}$ and $\mathbf{X I}$ were obtained in almost equimolar amounts; moreover, also a small amount of the isomerized olefin XII was detected in the mixture. To our knowledge, olefin IX has never been hydroformylated and the formation of the branched aldehyde $\mathbf{X}$, sterically unfavoured, as the prevailing product, is rather intriguing. We could infer this result to the isomerizing capability of our catalytic system, demonstrated also by the presence of the olefin XII in the reaction mixture. However, when 


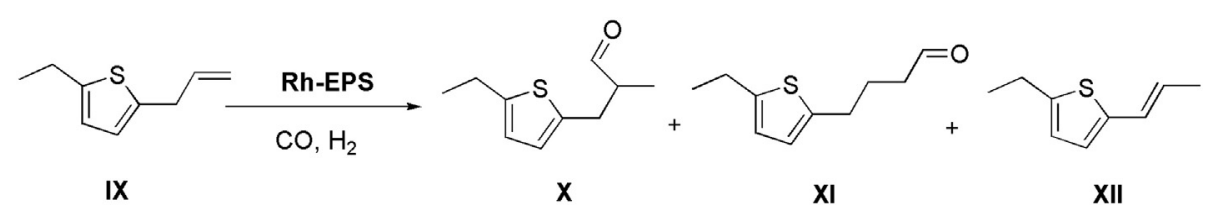

Scheme 3. Hydroformylation of 2-allyl-5-ethylthiophene (IX).

we tried to hydroformylate olefin XII, no oxo-product was obtained. This fact can be due to the high sensibility of Rh-EPS to the steric effects, however demonstrated by the inactivity towards other sterically hindered substrates as 1,1-diphenylethene, 1,3-diisopropenylbenzene and 2-(1-phenylvinyl)pyridine. Moreover, the internal olefin XII presents a less flexible structure with respect to the terminal olefin IX, so rendering more difficult interaction with a complex catalytic system as Rh-EPS. Therefore, we can ascribe the high amount of the branched aldehyde $\mathbf{X}$ to the great affinity of the "soft" metal rhodium for the sulfur atom [33]: the coordination of $\mathrm{S}$ to Rh could help the interaction of the catalytically active metal with the carbon atom in $\beta$-position to the thiophenyl ring. The aqueous phase containing Rh-EPS was reused for two consecutive experiments but, unfortunately, the activity of the catalytic system strongly decreased since the first recycling reaction (Entry 2, Table 3). Up to now we have no clear explanation of this phenomenon but we can hypothesize a sulfur poisoning of the catalyst via a competitive absorption onto rhodium metal active sites [34,35]; in particular the thiophene ring may affect the weak coordination of the metal to the oxygen groups present in the sugar, so determining a change in the structure of the catalyst that results negative for the activity.

\section{Conclusions}

Our strategy to generate metal binding exopolysaccharides in the direction of developing new catalysts able to work under biphase waterorganic solvent conditions was applied with success to prepare a new rhodium species which catalyzed the hydroformylation reaction of some model olefins. Peculiar stereo- and regio-selectivity with aliphatic olefins and with olefins containing a heteroaryl moiety in beta position was observed while no activity was found with some sterically hindered substrates. In some cases a fine recycling ability of the catalyst was found.

Supplementary data to this article can be found online at http://dx. doi.org/10.1016/j.catcom.2015.08.001.

\section{Acknowledgments}

We are grateful to Dr. Laura Sperni (Ca' Foscari University, Venice) for GC-MS analyses. We thank also Mrs. Barbara Vicentini (Ca' Foscari University, Venice) for IR spectra.

L.A. is indebted to Italian MIUR for financial support through the FIRB Riname (grant number RBAP114AMK) project. M.R. is indebted to the University of Padova (Italy) for a Senior Research Grant.

\section{References}

[1] P.W.N.M. van Leeuwen, C. Claver (Eds.), Rhodium Catalyzed Hydroformylation, Kluver Academic Publishers, Dordrecht, 2000.

[2] B. Cornils, W.A. Herrmann, I.T. Horvath, W. Leitner, S. Mecking, H. Olivier-Bourbigou, D. Vogt (Eds.), Multiphase Homogeneous Catalysis, Wiley-VCH, Weinheim, 2005.

[3] D. Cole-Hamilton, R. Tooze (Eds.), Catalyst Separation, Recovery and Recycling, Springer, Dordrecht, 2006.

[4] E. Kuntz, (Rhône-Poulenc Ind.), Fr. Pat. 2314910, 1975; DE 2627354, 1976.

[5] J. Steinreiber, T.R. Ward, Coord. Chem. Rev. 252 (2008) 751-766.

[6] S. Paganelli, M. Marchetti, M. Bianchin, C. Bertucci, J. Mol. Catal. A Chem. 269 (2007) 234-239.

[7] C. Bertucci, C. Botteghi, D. Giunta, M. Marchetti, S. Paganelli, Adv. Synth. Catal. 344 (2002) 556-562.

[8] M. Marchetti, F. Minello, S. Paganelli, O. Piccolo, Appl. Catal. A Gen. 373 (2010) 76-80.

[9] S. Paganelli, L. Spano, M. Marchetti, O. Piccolo, Chim. Ind. 87 (2005) 94-98.

[10] D.J. Macquarrie, J.J.E. Hardy, Ind. Eng. Chem. Res. 44 (2005) 8499-8520.

[11] S.-S. Yi, D.-H. Lee, E. Sin, Y.-S. Lee, Tetrahedron Lett. 48 (2007) 6771-6775.

[12] S.E.S. Leonhardt, A. Stolle, B. Ondruschka, G. Cravotto, C. De Leo, K.D. Jandt, T.F. Keller, Appl. Catal. A Gen. 379 (2010) 30-37.

[13] W.-L. Wei, H.-Y. Zhu, C.-L. Zhao, M.-Y. Huang, Y.-Y. Jiang, React. Funct. Polym. 59 (2004) 33-39.

[14] K.R. Reddy, N.S. Kumar, P.S. Reddy, B. Sreedhar, M.L. Kantam, J. Mol. Catal. A Chem. 252 (2006) 12-16.

[15] B.C.E. Makhubela, A. Jardine, G.S. Smith, Green Chem. 14 (2012) 338-347.

[16] G. Morris, S.E. Harding, in: M. Schaecter (Ed.), Encyclopedia of Microbiology, third ed.Elsevier Inc. 2009, pp. 482-494.

[17] S. Leone, C. De Castro, M. Parrilli, F. Baldi, R. Lanzetta, Eur. J. Org. Chem. (2007) 5183-5189.

[18] F. Baldi, D. Marchetto, D. Zanchettin, E. Sartorato, S. Paganelli, O. Piccolo, Green Chem. 12 (2010) 1405-1409.

[19] S. Paganelli, O. Piccolo, F. Baldi, R. Tassini, M. Gallo, G. La Sorella, Appl. Catal. A Gen. 451 (2013) 144-152.

[20] N.A. Bumagin, A.N. Kasatkin, I.P. Beletskaya, Russ. Chem. Bull. 33 (1984) 1696-1703.

[21] S.-I. Murahashi, M. Yamamura, K-Ichi Yanagisawa, N. Mita, K. Kondo, J. Org. Chem. 44 (1979) 2408-2417.

[22] D. Briggs, M. Seah, Practical Surface Analysis, Wiley, Chichester, 1990.

[23] C. Whitfield, Annu. Rev. Biochem. 75 (2006) 39-98.

[24] G.K. Sankaran, K.S. Viswanathan, C.K. Mathews, Appl. Spectrosc. 48 (1994) 7-12.

[25] H.S. Levinson, I. Mahler, FEMS Microbiol. Lett. 161 (1998) 135-138.

[26] L.E. Macaskie, R.M. Empson, A.K. Cheetham, C.P. Grey, A.J. Skarnulis, Science 257 (1992) 782-784.

[27] J.F. Moulder, W.F. Stickle, P.E. Sobol, K.D. Bomben, Handbook of X-ray Photoelectron Spectroscopy, in: J. Chastain (Ed.) Physical Electronics, Eden Prairie, MN, 1992.

[28] C.K. Chauhan, K.C. Joseph, B.B. Parekh, M.J. Joshi, Indian J. Pure Appl. Phys. 46 (2008) 507-512.

[29] P.W.V.M. van Leeuwen, Homogeneous Catalysis, Kluwer Academic Publishers, Dordrecht, 2004.

[30] S.L. Desset, S.W. Reader, D.J. Cole-Hamilton, Green Chem. 11 (2009) 630-637.

[31] K.-C. Song, J.Y. Baek, J.A. Bae, J.-H. Yim, Y.S. Ko, D.H. Kim, Y.-K. Park, J.-K. Jeon, Catal. Today 164 (2011) 561-565.

[32] L. Turin, Flexitral, Inc., US 7342042 B2, 2008.

[33] S.G. Murray, F.R. Hartley, Chem. Rev. 81 (1981) 365-414.

[34] K. Tomishige, M. Asadullah, K. Kunimori, Catal. Today 89 (2004) 389-403.

[35] S. Cimino, R. Torbati, L. Lisi, G. Russo, Appl. Catal. A Gen. 360 (2009) 43-49. 